\title{
REFLECTIVE AND REFLEXIVE APPROACHES TO \\ MICROCOMPUTER GRAPHICS: A STUDY COMPARING \\ LOGO TURTLE GRAPHICS PROGRAMMING AND PAINT GRAPHICS \\ SOFTWARE IN TEACHING ART CONCEPTS \\ TO SIXTH GRADE STUDENTS
}

\section{Kenneth Sakatani}

I am convinced that the movement towards educational

technology is irreversible and that our obligation as

educators is to learn how to deal with it - how, if you

like, to live with it as fully conscious human beings

working to enable other human beings to become conscious,

to become responsible, to learn, (Greene, 1968, p. 136).

The words of Maxine Greene, a philosopher from Teachers College, Columbia University, reflect the sentiments of many teachers who have resolved to use technology with their students in ways that are personally and educationally meaningful. As an arts educator, I have been interested in exploring how technological media, such as film, video, and computers, can be used to assist students in learning about art. My specific interest has been in investigating what role the microcomputer can play in teaching art concepts to children.

With the advent and use of the microcomputer in the art classroom, there has been much written about the computer in art education, particularily about the use of microcomputer graphics in studio art production (Hubbard and Boley, 1983; Semrau, 1984; McCulloch, 1984; Gartel, 1984; and, Pauler-Stovall, 1985). However, the microcomputer is not just another art medium for creative expression. Alan Kay and others (e.g., Kay, 1977; Sasowsky, 1985) visualize the role of the microcomputer as a tool to assist in symbolic manipulation and conceptualization, as well as a device for storing and retrieving art information. Madeja (1983) has commented 
that there is very little practical research on how microcomputers might be used to assist in developing aesthetic perception and response to art or in teaching art concepts to students.

The specific problem of the study, then, was to investigate whether two different approaches to microcomputer graphics, LOGO turtle graphics programming and "Paint" graphics software, would have any effect on how students respond to and describe formal art concepts as found in works of art. Formal art concepts were defined as the art elements of Color, Line, and Shape and art principles, such as Variety, Balance, Rhythm and Proportion.

The two computer graphics approaches, LOGO turtle graphics programming and Paint graphics software, were chosen for their inherent and distinctive characteristics. For example, by programming with LOGO turtle graphics, students create and type into a computer a series of procedures that control an electronic cursor or "turtle". By following these procedures or steps, the "turtle" electronically draws on the monitor screen. "Paint" graphics software, in contrast, provides students with ready-made design commands which they can use to draw images via an input device like a touch tablet. Unlike other art media, these two approaches to microcomputer graphics allow students to interact with the image in unique ways.

Both approaches to computer graphics, LOGO programming and "Paint" graphics, present to the student new ways of contemplating visual information through electronically created visual imagery. In looking at and describing works of art, we tend to identify and categorize this type of information as concepts such as line, shape, and color and to relate them to other organizing principles like balance and rhythm. By perceiving these visual concepts and relationships through the computer, students have to think about them in a different way. Rudolf Arnheim (1969) has long argued that our sensory perceptions are closely linked to how we think, and that there must be a balance between our intellect and intuition for any kind of 
productive thinking to occur.

LOGO turtle graphics and "Paint" graphics provide some possibility of achieving that intellectual and intuitive harmony. LOGO can be described as a reflective or deliberate process of juxtaposing two symbol systems, spatial images and written commands, in a context requiring active translation from one system to another, (Dickson, 1985). Student learners are, as a result, forced to deal with symbolic information within a context of creative problem-solving. Bork (1981) found that his college students seemed to develop more of their insight and intuition in solving design problems as a result of working in tandem with computer-generated alphanumeric and visual icons than through conventional methods. Within this dual mode of conception, Seymour Paper (1980) claims LOGO creates a "Microworld" environment for the student to personally describe and discover for his or her self new conceptual relationships.

"Paint" graphics software, on the other hand, can be characterized as reflexive or more spontaneous in style, as compared with LOGO turtle graphics. "Paint" graphics can be used to quickly generate, change, and modify visual images. Since graphic commands and design programs are already pre-programmed, "Paint" software is relatively easy to learn and use. Unlike the use of other traditional art media, such as paint and clay, students working with "Paint" graphics are not handicapped by a lack of art talent or technical art abililty. Students who have been exposed all their lives to television and other electronic media are usually curious and excited about using the computer to make images. Thet are not intimidated by this new medium. As a result, students are motivated to freely visualize and express artistic concepts without fear of failure.

Within the art education literature, programming and paint graphics systems in general are seen as two viable approaches for the use of microcomputer graphics in art instruction. Hubbard (1985) 
advocates that art students learn to program in order to thoroughly understand the computer. He even feels art teachers should take a leading role in developing mandatory computer literacy courses as a way of justifying art in the school curriculum. White (1985) argues that art teachers and students do not need extensive background in computer programming, nor have to purchase expensive computer graphics systems. His alternative is to use inexpensive touch tablet graphics systems such as Koala Touch Tablet and Microlllustrator software.

Research and curriculum development in the use of microcomputer graphics relevant to this study was limited. Stokrocki (1986) described a small group of gifted and talented adolescents in a microcomputer graphics program. Her qualitative study provided some useful information and insight into how students interact with computers in an art situation. Vaidya and Mckeeby (1984) investigated the effects of LOGO turtle graphics on children's thought processes, and the images they create through hand drawing. They believed the experiences with LOGO had an effect on the conceptualizations of the children's images. Using LOGO turtle graphics programming and traditional art media, Sharp (1984) attempted to influence students' art and their aesthetic values by having them interact with art and computers.

For this study, an art curriculum was designed and developed to teach 6th grade students to respond to and describe formal art concepts, such as color, line, and shape, in relation to other design principles, such as variety, rhythm, balance, and proportion, as found in works of art. Students studied these art concepts and principles by (1) engaging in individual and group discussions about works of art, (2) participating in non-studio art activities designed to foster awareness of art concepts in works of art; and, (3) by solving visual problems through the use of one of the following art media:

Traditional art media (e.g., tempera paint, crayons, ink and pen LOGO turtle graphics (C yber-LOGO turtle graphics software) 
"Paint" graphics (Microlllustrator software/Koala Touch Tablet)

Fifty (50) middle school 6th graders were randomly assigned to 3 treatment groups: LOGO, PAINT, and TRADITIONAL ART, after controlling for sex and academic achievement. A control group was also selected, which had no art or computer experience. Forty-six (46) complete sets of scores for the pre-, post-, and post-post tests were obtained from the original group of 50 students. There were 10 subjects in the LOGO group, and 12 subjects in each of the treatment groups, PAINT and TRADITIONAL ART, and also the Control group.

Students in the 3 treatment groups, LOGO, PAINT, and TRADITIONAL ART, were given 2 weeks of instruction in their assigned art medium or computer graphics approach, 6 weeks of daily curriculum instruction and activities, and then 1 week of follow-up activities. The same curriculum was given to these three groups. The only difference among the treatment groups was the art medium used in activites designed to reinforce the student learning of art. For example, the LOGO group worked exclusively with LOGO turtle graphics programming, the PAINT group worked only with "Paint" graphics software, and the TRADITIONAL ART students with art media, such as paints and brushes, in solving visual problems related to the art concept they had previously studied in a work of art.

The 3 treatment groups were administered a pre-, post-, and post-post test. Scores for the Control group were taken only during the post-test. The test consisted of showing an individual student three different works of art, one at a time. These works of art represented 3 different art styles, Realism, Surreal, and Abstract. The student was asked questions based on the description, interpretation, and judgment of each work of art. Three different sets of pictures, or a total of nine pictures, were shown for the 3 test periods.

Student talk about these works of art was recorded, transcribed, and scored based upon 17 descriptive attributes adopted from Acuff and 
Sieber-Suppes (1972). From these original attributes, 8 variables were derived for analysis. These eight variables were composed of Color, Line, Shape, Material, Literal, Organizational, Expressive, and Contextual attributes.

Analyses of variance were carried out, using the 8 variables as the dependent variable. The first analysis was a 3-way ANOVA with repeated measures on style, curriculum, and time. The main interest was to examine if there were significant effects of the curriculum for any of the 8 variables at the .05 level.

In general the analysis did not show many curriculum effects for the 8 variables, although there were some curriculum interactions with time and style. Since some of the results from the first ANOVA may have been diluted by pooling over time, a second analysis was done examining each test administration from post- to post-post test. This analysis revealed more about the effects of the curriculum in relation to other factors. For example, for the Literal variable, at the post-test, there was a marginal effect for curriculm $(p=.08)$ and a style and curriculum interaction $(p=.001)$. There was also a significant interaction between style and curriculum at the post-post test for Line variable. This suggests that these effects might have been due more to one specific style of painting, rather than the curriculum treatment itself; and that some students might have been focusing on one particular style during the test.

There were significant curriculum effects $(p=.009)$ at the post-test for the Line variable. Post-hoc comparisions among groups revealed that the PAINT group was significantly higher at the .05 level from the Control group. The LOGO and TRADITIONAL ART groups were not significantly different from the Control. For the Shape variable, there were significant effects of curriculum $(p=.021)$ and style $(p=.001)$ at the post-test. Post-hoc comparisons of the groups for the Shape variable showed that the PAINT group was again significantly higher than the Control. The two other treatment 
groups, LOGO and TRADITIONAL ART, were not significantly higher than the Control group.

These preliminary results suggest that the curriculum had the most effect on those students who used the "Paint" graphics approach in relation to the variables of Line and Shape. For the Color variable, the analysis did not exhibit any significant differences among groups. We could assume that this concept was already quite familiar to students; and therefore, the differences among groups for this variable from post- to post-post test would not indicate significant differences. In other words, these results indicate a "ceiling" effect might have occurred for the Color variable.

We might further speculate that the "Paint" graphics software allows students to better visualize art concepts, due to its ease of use mentioned earlier. This motivational factor, involved with the use of microcomputer graphics, seems to encourage students to think about and experiment more with visual concepts. Computer graphics, like "Paint" graphics software, acts as a tool for "cognitive visualization."

This study suggests that art educators, through pre- and in-service training might become more aware of the microcomputer and the possible role it might play in assisting students in learning about art. Given the increased use and popularity of the microcomputer in the art classroom, it is important that further research examine the educational advantages and problems of using the microcomputer, particularly microcomputer graphics, in all areas of the art curriculum. Eisner (1983) envisions that a new set of technological tools makes it possible to think of new ends, and at the same time, the possibilities and limitations of the technology circumscribe what the user can do with it as an expressive medium. As art educators, we must formulate worthwhile goals and objectives so that a tool, such as the microcomputer, may be used toward productive ends in art. 


\section{References}

Acuff, Bette C. and Sieber-Suppes, Joan, A Manual for Coding

Descriptions, Interpretations, and Evaluations of Visual Art Forms,

Research and Development Memorandum No. 95, Stanford: Stanford University, 1972.

Arnheim, Rudolph, Visual Thinking, Berkeley, University of California Press, 1969.

Bork, Alfred, Learning with Computers, Massachusetts, Digital Press, 1981.

Dickson, Patrick W., "Thought-Provoking Software: Juxtaposing Symbol Systems," Educational Researcher, Volume 14, Number 5, May 1985, pp. 30-38.

Eisner, Elliot W., "The Invention of Mind: Technology and the Arts," Educational Digest, Volume 49, September 1983, pp. 11-14.

Gartel, L. M., "Computer Graphics Evolution: A Survey," School Arts, Volume 84, February 1985, pp. 35-37.

Greene, Maxine, "Technology and the Human Person," Technology and the Curriculum, Paul W. F. Witt, Ed., New York: Teachers College Press, 1968.

Hubbard, Guy, "Computer Literacy and the Art Programm," Art

Education, Volume 38, Number 2, March 1985, pp. 15-18. Hubbard, Guy and Boley, E., "Computer Graphics and Art Education," School Arts, Volume 83, Number 3, November 1983, pp. 18-21. Kay, Alan C., "Microelectronics and the Personal Computer,"

Scientific American, Volume 237, Number 20, September 1977, pp. 124-135.

McCulloch, W., "A Change of Image: Computers in the Art Room," Art Education, Volume 37, July 1984, pp. 44-46.

Madeja, Stanley S., "Computer Graphics: The New Subject Matter for the Art Curriculum," Art Education, Volume 36, May 1983, pp. 15-17.

Papert, Seymour, Mindstorms: Children, Computers, and Powerful 
Ideas. New York, Basic Books, Inc., 1980.

Pauler-Stovell, Donna, "A Computer Art Station in the Artroom,"

School Arts, Volume 85, Number 6, February 1985, pp. 10-12.

Sasowsky, N., "The Computer and the Art Teacher," School Arts, Volume 84, February 1985, pp. 10-12.

Semrau, P., "Computers: Potential for Teaching Art," Arts and

Activities, Volume 95, April 1984, pp. 30-31.

Sharp, Pamela, "Using LOGO to Shape Artistic Ideas," Classroom

Computer Learning, Volume 5, September 1984, pp. 60-62.

Stokrocki, Mary, "Qualified Interpretation of a Microcomputer Graphics

Course for Gifted and Talented Adolescents," Art Education, Volume

39, Number 1, January 1986, pp. 44-47.

Vaidya, Sheila and Mckeeby, John, "Computer Turtle Graphics: Do They

Affect Children's Thought Processes?" Educational Technology,

Volume 24, September 1984, pp. 46-47.

White, Dennis W., "Creating Graphics with the Koala Pad," Art

Education, Volume 38, March 1985, pp. 10-14. 